Running head: BILINGUAL WORD RECOGNITION IN SENTENCES

\title{
Visual Word Recognition by Bilinguals in a Sentence Context: Evidence for Non-selective Lexical Access
}

\author{
Wouter Duyck, Eva Van Assche, Denis Drieghe, \& Robert J. Hartsuiker
}

Ghent University, Belgium

Correspondence Address:

Wouter Duyck

Department of Experimental Psychology

Ghent University

Henri Dunantlaan 2

B-9000 Ghent (Belgium)

E-mail: wouter.duyck@UGent.be

Tel.: 32-9-264-64-35 - Fax: 32-9-264-64-96 


\begin{abstract}
Recent research on bilingualism has shown that lexical access in visual word recognition by bilinguals is not selective with respect to language. The present study investigated language-independent lexical access in bilinguals reading sentences, which constitutes a strong unilingual linguistic context. In the first experiment, Dutch-English bilinguals performing a L2 lexical decision task were faster to recognize identical and non-identical cognate words (e.g. banaan - banana) presented in isolation than control words. A second experiment replicated this effect when the same set of cognates was presented as the final words of low-constraint sentences. In a third experiment using eyetracking, we showed that early target reading time measures also yield cognate facilitation, but only for identical cognates. These results suggest that a sentence context may influence, but does not nullify, cross-lingual lexical interactions during early visual word recognition by bilinguals.
\end{abstract}

Keywords: bilingualism, visual word recognition, sentence context, cognate 


\section{Visual Word Recognition by Bilinguals in a Sentence Context:}

\section{Evidence for Non-selective Lexical Access}

During the last decade, research on visual word recognition in bilinguals has been dominated by studies investigating whether both languages are processed by functionally and structurally independent systems or not. The most intuitively appealing theory about this issue would probably be that bilinguals have two separate language systems and lexicons: one for the native language (L1) and one for the second language (L2). However, a lot of evidence has been gathered against this hypothesis: interlingual interactions have been observed at different representational levels, even when bilinguals are processing unilingual sets of words and therefore have no reason to keep an irrelevant language active. Thus far, the majority of these studies have focused on orthographic lexical representations. They have consistently shown that access to these representations is not language specific. Orthographic lexical representations from L2 are accessed during (and interact early with) L1 reading and vice versa (e.g., Dijkstra, Timmermans, \& Schriefers, 2000; Dijkstra, Grainger, \& Van Heuven, 1999; Van Hell \& Dijkstra, 2002; for a recent review, see Dijkstra \& Van Heuven, 2002). Recently, a few studies have shown that the languageindependent lexical access claim also holds for phonological representations. For example, Duyck (2005) has shown that masked nonword primes are coded through L1 grapheme conversion rules when reading L2 target words (and vice versa), suggesting that phonological representations from one language may be activated when reading in another language (see also Jared \& Kroll, 2001).

Because the ongoing debate has almost been settled in favor of this language-independent lexical access hypothesis (for both orthographic and phonological lexical representations), it may be time to put into question the ecological validity and generalizability of these studies on lexical autonomy. Whereas almost all these studies have investigated the recognition of words presented in isolation, word recognition in both L1 and L2 rarely occurs out of context. Words are almost always embedded in meaningful sentences and these may constitute an important influence on lexical access in general and on the degree of cross-lingual lexical interactions in particular. From the monolingual domain it is well known that the semantic and syntactic framework that one constructs when reading a sentence provides an important top- 
down influence on lexical access of the words appearing further in the sentence. For example, there is ample evidence that more predictable words are processed faster in a variety of production and recognition tasks such as naming (e.g., McClelland \& O'Regan, 1981; Stanovich \& West, 1983), lexical decision (e.g., Fischler \& Bloom, 1979; Fischler \& Bloom, 1980; Schwanenflugel \& Lacount, 1988; Schwanenflugel \& Shoben, 1985) and speech monitoring (e.g., Cole \& Perfetti, 1980). Similarly, eyetracking studies have consistently shown that more predictable words are skipped more often, and yield shorter fixation times (e.g., Balota, Pollatsek, \& Rayner, 1985; Ehrlich \& Rayner, 1981; Rayner \& Well, 1996). These studies show that readers use sentence contexts to generate semantic, syntactic and lexical feature restrictions to facilitate the processing of subsequent expected words (e.g., Schwanenflugel \& Lacount, 1988; see also Schwanenflugel \& Shoben, 1985; Stanovich \& West, 1981). Importantly for the present study and for the issue of language-independent lexical access in bilinguals, these findings also suggests that it may be plausible to assume that bilinguals use the language of a sentence as a language cue to direct lexical access of words appearing later in the sentence. Limiting or focusing lexical search to representations from a specific language would be very economical, because bilinguals have to consider almost twice as many lexical representations during word recognition than monolinguals (e.g., Gollan, Montoya, FennemaNotestine, \& Morris, 2005).

Interestingly, Altarriba, Kroll, Sholl and Rayner (1996) showed that lexical representations from a specific language may indeed be selectively inhibited during lexical retrieval processes which interact with higher level (semantic) sentence context effects. Using eyetracking with Spanish-English bilinguals, they found that the recognition of code-switched (or mixed-language) L1 words inserted in high-constraint L2 sentences is inhibited (relative to the same words embedded in low-constraint sentences). For example, processing of the L1 word dinero is inhibited in the sentence He wanted to deposit all of his DINERO [money] at the credit union, even though that L1 word meets the semantic and syntactic feature restrictions imposed by the sentence. Because processing of the L2 translation equivalent money in the same sentence does not yield inhibition, but facilitation, this shows that sentence contexts may indeed inhibit activation of lexical representations in a non-target language, so that only lexical representations belonging to the 
sentence language become activated during recognition. This suggests that the language of a sentence may indeed be used as a cue to guide lexical access. However, whereas the study of Altarriba et al. (1996) provides evidence for this general principle, because it used code-switched, high-constraint sentences , it cannot provide an answer to the question of lexical autonomy in regular, unilingual language processing with less artificially constrained sentences.

Similar context effects on the degree of cross-lingual activation, but not imposed by a linguistic sentence context, have been reported for example by Jared and Kroll (2001). Using English-French bilinguals, they showed that L1 words with L2 word-body enemies (e.g. the word bait contains the letter sequence ait, which is pronounced differently in French) are named slower than controls, but only after participants named a block of L2 filler words prior to the experiment. Similarly, Elston-Güttler, Gunter and Kotz (2005) found that the L1 meaning of interlingual homographs (words that are written the same but have different meanings across languages, e.g. room, which means cream in Dutch) is activated during L2 processing, but only during the first half of the L2 experiment, and only for participants who saw a L1 movie instead of a L2 movie prior to the experiment. These studies also show that non-target language lexical activation may indeed be susceptible to language context. For a theoretical account of possible linguistic and non-linguistic context effects on selective lexical access during bilingual word recognition, we refer to our discussion of Dijkstra and Van Heuven's BIA+ model (e.g., Dijkstra et al., 1999; Dijkstra \& Van Heuven, 2002) in the General Discussion section.

It is clear that none of these studies investigating context effects on non-target language activation directly assesses the linguistic context effect of unilingual sentences on cross-lingual lexical interactions during recognition of words embedded in these sentences. Therefore, it is the goal of the present study to test whether bilinguals use the language of a sentence as a linguistic cue to guide lexical access in unilingual sentence processing. It may be the case that lexical access in visual word recognition by bilinguals is language-independent in isolation, but that the unilingual linguistic context in real life sentence processing is so strong that lexical representations from another language have virtually no effect on word recognition in (sequences of) unilingual sentences. Surprisingly, there are very few data on this issue, which 
contrasts with the large number of studies in the monolingual domain that investigated sentence context effects on lexical access. However, it would seriously limit the relevance and ecological validity of the findings in isolated bilingual word recognition if no reliable evidence for language-independent lexical access in a sentence context can be obtained.

Before we discuss the very few earlier studies on word recognition by bilinguals in a sentence context and go into more detail about the present study, we will briefly summarize the main experimental findings in isolated word recognition. This enables us to establish a reliable marker of languageindependent lexical access for use in the sentence studies of this paper.

\section{Language-independent Lexical Access: Studies on Isolated Word Recognition}

To our knowledge, the first study on lexical autonomy is that of Caramazza and Brones (1979). They investigated lexical access in Spanish-English bilinguals by looking at the recognition of cognate words. These are translation equivalents which also share orthography and/or phonology across languages (e.g. a Dutch-English cognate is lip). They found that bilingual participants responded more quickly to L2 cognates than to L2 control words in a lexical decision task. Such a cognate facilitation effect is commonly attributed to the fact that the L1 lexical representation of the cognate is also activated to a certain degree during L2 word recognition, and spreads some of this activation to the L2 lexical representation of the cognate. Hence, they were the first to find evidence for the currently dominant theory that access to lexical representations in bilinguals is not language-specific ${ }^{1}$. Later, several authors replicated this cognate facilitation effect in L2 (e.g. Dijkstra et al., 1999; Lemhöfer \& Dijkstra, 2004; Schwartz \& Kroll, 2006). Also, Lemhöfer, Dijkstra and Michel (2004) showed that this effect may accumulate over languages: using Dutch-English-German trilinguals, they reported faster responses to L3 words which are cognates with both L1 and L2 than for exclusive L3-L1 cognates.

Initially, no cognate facilitation effect was found in L1 (e.g., Caramazza \& Brones, 1979; Cristoffanini, Kirsner, \& Milech, 1986) However, better controlled studies have recently reported evidence that does support this strong test of non-selective lexical access. Testing Dutch-English-French trilinguals, 
Van Hell and Dijkstra (2002) found a facilitation effect for L1 words that were cognates with respect to L2 (for similar results, see Font, 2001). Also, the same effect was replicated for L1-L3 cognates, but only for participants that were very proficient in French (L3). These are very noteworthy results, because their critical stimuli were mostly near-cognates (85\% and $75 \%$ for L2 and L3 respectively), which are not completely orthographically (and phonologically) identical (e.g. Dutch-English: bakker - baker; DutchFrench: muиr - mur). Surprisingly, the cognate effect survived these differences, suggesting that there is also strong activation spreading between representations of near-cognates. Van Hell and Dijkstra attributed the apparent contradiction between their symmetric cognate facilitation effect and the earlier asymmetric cognate effects to a possible influence of language proficiency: their L1-L3 cognate facilitation effect was only significant with bilinguals who were quite proficient with respect to L3. So apparently, the occurrence of cross-language lexical interactions in L1 processing requires a certain level of L2/L3 proficiency.

In all of the previously mentioned studies, the critical words (cognates) are often overlapping across languages with respect to orthographic, phonological and semantic representations. Therefore, the cognate facilitation effect probably originates from convergent activation spreading across languages from all of these representational levels. The first study that systematically manipulated the cross-lingual overlap for these different levels is that of Dijkstra et al. (1999). Using a lexical decision task with Dutch-English bilinguals, they investigated the recognition of L2 words that varied on the degree of cross-lingual overlap with respect to semantics $(\mathrm{S})$, orthography $(\mathrm{O})$ and phonology $(\mathrm{P})$. They also obtained a cognate facilitation effect (SOP and SO items). Contrastingly, words that only shared phonology (P) across languages were recognized slower (interlingual homophones, e.g. leaf and lief [sweet]). Combinations of phonological overlap with either orthography or semantics (OP and SP items) did not yield reliable effects. A follow-up study by Lemhöfer and Dijkstra (2004) reported comparable findings for similar SOP-items, but they did not replicate the inhibition effect for P items. Also, Schwartz and Kroll (2006) found faster RTs for SOP than for SO cognates, suggesting phonological facilitation in the presence of SO overlap, instead of inhibition. Mixed results were also obtained in studies that focused more on exclusive orthographic interactions (the $\mathrm{O}$ dimension) across languages, typically by looking at interlingual homographs. These 
studies have yielded homograph inhibition effects (e.g., Jared \& Szucs, 2002), null effects (e.g., Altenberg \& Cairns, 1983), or facilitation effects, depending on task demands and stimulus list composition (e.g., Dijkstra, Van Jaarsveld, \& Ten Brinke, 1998; Dijkstra, De Bruijn, Schriefers, \& Ten Brinke, 2000; Dijkstra et al., 2000). This complicated pattern of results contrasts with the consistent replication of cognate facilitation effects and suggests it is unadvisable to use homograph instead of cognate processing when studying lexical autonomy in a sentence context.

Whereas the most convincing and consistent body of evidence comes from the cognate facilitation effect, it is important to note that the evidence for language-independent lexical access in word recognition by bilinguals is not restricted to cognate effects. Van Heuven, Dijkstra and Grainger (1998) proposed a different and elegant way to investigate this issue. They started from the common finding in monolingual research that word recognition depends on a word's neighborhood size (i.e. the number of words which are orthographically identical except for one letter, e.g., Grainger, 1990). Van Heuven et al. orthogonally manipulated targets' neighborhood size in both L1 and L2 and found that word recognition depends on the neighborhood size of the word in both languages, showing that L1 (Dutch) word forms were activated during L2 (English) word recognition.

Finally, these findings from the visual word recognition literature have analogues in auditory word recognition. The most convincing evidence here comes from a series of studies by Marian and colleagues (Marian \& Spivey, 2003; Marian, Spivey, \& Hirsch, 2003; Spivey \& Marian, 1999). Using an eyetracking paradigm with real objects, they repeatedly found that participants instructed in L2 to pick up target objects, often looked at distractor objects that were phonologically similar in L1 to the respective L2 target. For example, Russian-English bilinguals instructed in English to "pick up the marker" often looked at a stamp, because its Russian translation equivalent (marka) is phonologically similar to the English target word marker. Similar results were obtained by Weber and Cutler (2004). Using a picture version of the same paradigm, they also found that Dutch-English bilinguals hearing English (L2) target words (e.g. desk) made longer eye fixations on distractor pictures with Dutch (L1) names phonologically related to the English target (e.g. a picture of a deksel [lid]). Note that in the studies of Marian and colleagues, the short 
imperatives (such as pick up the [target]) are repeated across trials, and can hardly be considered a meaningful sentence context. In fact, Marian and colleagues also only draw conclusions about their data with respect to word recognition, not sentence processing. Hence, these studies offer elegant auditory analogues for the findings in isolated visual word recognition, but they do not offer empirical evidence for the issue of sentence context effects on word processing (either visual or auditory).

In sum, it should be clear that lexical access in bilinguals is not language-specific. Effects of orthographic/phonological (either inhibitory or facilitatory) and semantic cross-lingual overlap have often been obtained in both L1 and L2 unilingual word recognition, even though information from the other language is not relevant for the task at hand. It is also clear that the degree of lexical selectivity is not a simple additive function of cross-lingual overlap on these three representational dimensions. Instead, the interactions between these dimensions may be very complex (see for example Dijkstra et al., 1999, and Schwartz \& Kroll, 2006, mentioned above). However, it can be concluded that the cognate facilitation effect, commonly interpreted as evidence against lexical autonomy, has consistently been replicated in a large number of studies using different languages, stimuli and tasks (e.g. lexical decision, see above; word translation, De Groot, Dannenburg, \& Van Hell, 1994, Sanchez-Casas, Davis, \& Garcia-Albea, 1992; picture naming, Costa, Caramazza, \& Sebastian-Galles, 2000 and progressive demasking, Dijkstra et al., 1999). Therefore, this effect may be considered a reliable benchmark test of lexical autonomy in a sentence context.

\section{Visual Word Recognition by Bilinguals in a Sentence Context}

Before we turn to the present study, it is important to briefly discuss what is known already about word recognition by bilinguals in a sentence context. Even though this is crucial for the generalizibility and ecological validity of the conclusions drawn from isolated word recognition studies, there are surprisingly few studies which have tackled this issue, in contrast with the monolingual domain.

The first study investigating sentence processing by bilinguals is that of Altarriba et al. (1996). As discussed earlier, they found that processing of code-switched L1 words in high-constraint L2 sentences is 
inhibited (e.g. He wanted to deposit all of his DINERO [money] at the credit union). Because these targets share all semantic and syntactic features with the expected L2 word, but still are inhibited, this offers evidence for the general principle that sentence contexts may be used by bilinguals to guide lexical access to representations belonging to the same language as the sentence in which target words are embedded. Importantly for the present study, a similar mechanism might come into play when reading unilingual sentences. Because bilinguals do not expect to see a L2 word when reading in L1 (or vice versa), the lexical representation of cognates in the non-target language (just as all other lexical representations in that language) might be inhibited when reading unilingual sentences, such that no cognate facilitation effect emerges. However, as noted earlier, because the study of Altarriba et al. used mixed-language highconstraint sentences, it does not provide a direct answer to the question of lexical autonomy in unilingual language processing with less artificially constrained sentences.

More direct evidence, using unilingual sentences, comes from Van Hell (1998; these data are also reported in Van Hell, 2005). Using Dutch-English bilinguals, she presented high and low-constraint L2 sentences in which a target word (embedded or at the end of the sentence) was replaced by dashes (e.g., $a$ green --- and a yellow banana lay on the fruit dish; target APPLE). After four seconds, the sentence was replaced by a centered target word on which the participants had to perform a lexical decision judgment. Target words were either cognates or control words. In low-constraint sentences, she replicated the cognate facilitation effect found in studies that presented words in isolation studies (see above). In high-constraint sentences, no cognate effect was found, suggesting that lexical access in L2 reading may still be influenced by semantic expectations. Similar findings for word production were recently reported by Schwartz and Kroll (2006). They found a similar cognate facilitation effect for target words appearing in the middle of a sentence in a L2 word naming task. Just as Van Hell (1998), they found that this cognate facilitation effect only emerged in low-constraint sentences.

To our knowledge, the only other data on bilingual lexical autonomy in a sentence context come from Elston-Güttler and colleagues (Elston-Güttler et al., 2005; see also Elston-Güttler, Paulmann, \& Kotz, 2005), who tested German-English bilinguals. These authors investigated the recognition of homographs in 
a L2 sentence context, using a lexical decision task. Triggered by a button press, these homographs were presented as the final words of a L2 sentence (e.g. The woman gave her friend an expensive gift), and served as the primes for targets that replaced the homographs. Target words could either refer to the L1 meaning of the homograph (e.g. POISON, the German meaning of gift) or not. When these prime-target pairs were presented in isolation, the L2 homograph always primed its L1 meaning, suggesting languageindependent lexical access. However, as noted earlier, homograph priming in a sentence context was only found during the first half of the experiment, for participants who saw a German movie prior to the experiment, increasing L1 salience. Elston-Güttler et al. (2005) claimed that participants adapted their lexical decision thresholds during the experiment and gradually "zoomed into" the all-L2 task. These findings show that the degree of cross-lingual interactions in the processing of homographs is very sensitive to top-down influences, which follows the mixed homograph findings in isolated word recognition. A final inconsistency lies in the fact that cross-lingual interactions were observed even though the sentences that Elston-Güttler et al. used were all quite high-constraint. This contrasts with Van Hell (1998; 2005), who only obtained a cognate facilitation effect with words appearing in low-constraint sentences.

\section{The Present Study}

There is a large body of evidence from the monolingual sentence processing domain that lexical access is guided by lexically, semantically and/or syntactically driven expectations generated through sentence context (e.g., Balota et al., 1985; Ehrlich \& Rayner, 1981; Fischler \& Bloom, 1980; McClelland \& O'Regan, 1981; Rayner \& Well, 1996; Schwanenflugel \& Lacount, 1988; Schwanenflugel \& Shoben, 1985; Stanovich \& West, 1983). In the present study, we investigated whether the language in which a sentence appears is used by bilinguals to guide lexical search/access towards lexical representations of a specific language. More specifically, the focus of this study was to investigate whether the linguistic context provided by a sentence nullifies activation in non-target language lexical representations, and resulting cross-lingual interactions, during recognition of words embedded in that sentence. If this is the case, lexical access in everyday reading by bilinguals may be functionally language-specific, even if it is not in isolation. 
At present, the only study that assessed such a linguistic sentence context effect in bilinguals is that of Altarriba et al. (1996) discussed above. However, because they used mixed-language sentences, this study cannot provide an answer to the issue of language-selective lexical access during unilingual language processing. Also, other studies focusing on context effects have investigated task demands, stimulus list composition (Dijkstra et al., 1998; Dijkstra et al., 2000) or non-target language salience (Elston-Güttler et al., 2005; Jared \& Kroll, 2001), but not effects of sentence contexts.

Because this is the first study trying to show language-independent lexical access in a sentence context using a lexical decision task (without words presented outside of the sentence) and normal reading, it was advisable to use a strong and reliable marker of cross-lingual interactions. Because earlier research, both in isolation (see above, e.g. Dijkstra et al., 2000) and in a sentence context (see above, e.g. ElstonGüttler et al., 2005), has shown that homograph effects are inconsistent and subject to top-down influences, we implemented the more reliable and consistent cognate facilitation effect found in single-word studies in a sentence context to maximize chances of observing cross-lingual interactions. This constitutes a first benchmark test of language selectivity of lexical access in a sentence context.

Because the cognate facilitation effect seems to be more reliable in L2 than in L1 (see above), we decided to use a L2 reading task. Similar to Van Hell and Dijkstra (2002), our stimuli were mostly nearcognates, which are orthographically/phonologically very similar, but not identical (e.g. ship - schip). This way, the experimental language context is almost strictly unilingual (probably more than everyday life texts) because the stimuli are unambiguous with respect to the language to which they belong. This is not the case in studies that used a high proportion of homograph stimuli (e.g., Elston-Güttler et al., 2005; Schwartz \& Kroll, 2006). This may be important because Grosjean (1997; see also Soares \& Grosjean, 1984) suggested that the degree of lexical autonomy depends on the 'language mode' that a bilingual is in: depending on the language context and the bilinguals' expectations, lexical access may be more or less selective. Therefore, our primarily near-cognate stimulus set, just as that of Van Hell and Dijkstra (2002), constitutes a very strong test of lexical autonomy. We did however include a few identical cognates as well, allowing us to investigate whether the degree of cross-lingual overlap interacts with the cognate effect in a 
sentence context. But, for the reasons outlined above, the proportion of language-ambiguous words (identical cognates) was kept extremely low (i.e., $6.67 \%$ of all word targets).

In our first experiment, we used a standard L2 lexical decision task (similar to that of Van Hell \& Dijkstra, 2002, for example) with word targets presented in isolation. This was necessary to validate our stimuli before using them in a sentence reading task. In the second experiment, we used a lexical decision task with the same word targets (cognates and controls) as final words of sentences presented through serial visual presentation (SVP) (see also Schwartz \& Kroll, 2006). Previous studies have demonstrated that this method is susceptible to lexical factors (Altarriba et al., 1996). Also, because of the fast rate of presentation, it is practically impossible for the participants to translate the sentence while reading. In the third experiment, we used an eyetracking paradigm, which is as close to normal reading as possible in an experimental setting, and excludes strategic processes specific to the lexical decision task. Also, in contrast with SVP, the same word targets were appearing somewhere in the middle of the sentences, and could not be identified (e.g., by using uppercase letters, Experiment 2), which also makes the task less similar to isolated lexical decision. This technique is more sensitive than the SVP experiment, and, by comparing different reading time measures, it allows for an assessment of the timecourse of cross-lingual lexical interactions. To our knowledge, this is the first study ever to investigate visual word recognition in a monolingual sentence context by bilinguals.

Because the aim of the present study is to investigate the exclusive influence of the linguistic contexts provided by sentences, we considered it important to exclude as much as possible all other possible top-down influences which might interact with this context effect and with target recognition. Therefore, we wanted to minimize semantically driven expectations with respect to the target word (e.g., see Altarriba et al., 1996), and only used low-constraint sentences, in which the target word is plausible, but not predictable. Also, note that the earlier bilingual sentence studies are quite inconsistent with respect to the effect of semantic constraint. For example, Van Hell (1998) (see also Schwartz \& Kroll, 2006) only obtained a cognate effect in low-constraint sentences, whereas Elston-Güttler et al. (2005) obtained their cross-lingual effects with homographs in high-constraint sentences. 
We believe this study constitutes a stronger test of lexical autonomy in a sentence context than the studies that tackled this issue earlier. First, in the studies of Van Hell (1998) and Elston-Güttler et al. (2005), participants had to respond to target words presented outside the actual sentence contexts, making the task more similar to isolated lexical decision. In the present study, target words were effectively embedded in the sentences (Experiment 2: final word targets; Experiment 3: embedded target words). Second, because both near-cognates and identical cognates were included in the materials, the present study will also investigate whether any cognate effect in sentence context interacts with form overlap between translation equivalents. No study has tested this so far. Third, because we only used low-constraint sentences, this study has the methodological advantage that cognate and control targets could be presented in the same sentence. In the studies of Van Hell (1998) and Schwartz and Kroll (2006), which also used high-constraint sentences, this was not the case. Of course, even with sentences matched for plausibility, length and target position, one cannot exclude with certainty that obtained cognate effects may be a partial confound of differing preceding words. Fourth, the study by Schwartz and Kroll (2006) used word naming, which also comprises a production component. Because the locus of the obtained cognate facilitation effect may also be situated in this production phase (as indicated by cognate effects in other production tasks, such as picture naming, e.g., Costa et al., 2000), the present study extends their findings for word production to pure visual word recognition (lexical decision, eyetracking). This allows to attribute any cognate facilitation effect more directly to the lexical access process. Fifth, it should also be noted that Schwartz and Kroll (2006) presented both homographs and cognates. Consequently, there were quite some language-ambiguous words in these experiments $(84.09 \%$ of all word targets: 22 homographs and 15 identical cognates, out of 22), which may have increased its salience relative to natural unilingual language contexts (see the language mode theory of Grosjean, 1997, discussed earlier). Because we did not present homographs, used mostly non-identical cognates and included L2 filler targets, our stimulus set was much more unambiguous with respect to language (e.g., Experiment 1: $6.67 \%$ of word targets were identical cognates). Finally, this is the first study to use eyetracking to tackle this issue. Because this technique 
allows participants to read normally as in everyday life, it excludes most factors inherent to experimental tasks as the source for cross-lingual lexical interactions.

\section{Experiment 1}

Experiment 1 constituted a replication of the L2 cognate facilitation effect (e.g., Dijkstra et al., 1999), to validate our stimulus set for use in the sentence studies.

\section{Method}

Participants. The participants were 36 Dutch-English bilinguals: 33 psychology students from Ghent University and 3 volunteers. The students participated for course requirements or a small monetary fee. Of these 36 participants, 2 were excluded because of poor performance in the lexical decision task (their mean error rate was more than 2.5 standard deviations above the overall mean error rate) All participants started to learn English in a scholastic setting around the age of 14-15 (formal English courses are mandatory at that age in the Belgian school system), and live in a L1 dominant environment, speaking Dutch at home, at school, with friends, etc. All of them are regularly exposed to their L2 (English) through Belgian popular media and entertainment (music, internet, films, television, etc.). Like almost everybody in Belgium, all participants also have some knowledge of French, but this was reported as their third language. Participants were asked to rate their L1 and L2 proficiency with respect to several skills (reading, writing, speaking, general proficiency) on a 7-point Likert scale ranging from 'very bad' to 'very good' after the actual experiment. Also, general L3 proficiency was assessed. Means are reported in Table 1. Mean selfreported, general L1 $(M=5.7)$, L2 $(M=4.9)$ and L3 proficiency $(M=4.1)$ differed significantly, all $p \mathrm{~s}<$ .001 , as shown by a sign test (because proficiency ratings did not meet the assumptions for parametric testing, proficiency differences were tested by non-parametric statistics). 
Stimulus Materials. The target stimuli consisted of 240 items: 30 Dutch-English cognates, 30 English (L2) control words, 60 L2 filler words (that did not exist in L1 or sounded like existing L1 words) and 120 nonwords. All targets were three to eight letters long. The cognates were selected from the cognate stimuli of Dijkstra et al. (1999) and Van Hell and Dijkstra (2002). A few additional items were extracted from the CELEX lexical database (Baayen, Piepenbrock, \& Van Rijn, 1993). We only selected those cognates for which a control word could be found meeting all the criteria mentioned below, and for which both the cognate and its control could be inserted in the same low-constraint sentence as the final word (Experiment 2) or one of the middle words (Experiment 3). This resulted in a list of 22 non-identical and 8 identical Dutch-English cognates. According to the word similarity measure developed by Van Orden $(1987)^{2}$, identical cognates $(M=1.0)$ and non-identical cognates $(M=0.75)$ differed significantly with respect to the word similarity with their translation equivalents $(p<.001)$. Using the WordGen stimulus generation program (Duyck, Desmet, Verbeke, \& Brysbaert, 2004), we generated a control word for each cognate (item by item), which was matched with respect to word length (identical), word frequency, number of syllables (identical), word class (all words were nouns), and neighbourhood size (Coltheart, Davelaar, Jonasson, \& Besner, 1977) (see Table 2). The cognates and control words did not differ from each other with respect to any of these variables (dependent samples sign tests yielded $p s>.64$ ). Also, identical and non-identical cognates did not differ on any of these variables (Kolmogorov-Smirnov tests yielded $p s>.46)$. The selected cognates and their control words are included in Appendix A.

Insert Table 2 about here

The English (L2) filler words were also randomly selected from the CELEX database. They were matched with the cognates and control words with respect to all of the parameters mentioned above ( $p$ s > .20). Using the WordGen program, 120 nonword targets were generated that were orthographically and phonologically legal in English. Again, they were matched with cognates and control words with respect to 
word length (identical), neighbourhood size and summated bigram frequency ( $p s>.55)$, which may be considered a measure of wordlikeness in a given language (Duyck et al., 2004).

Procedure. Participants were tested in small groups. It was not possible to see the computer screen of another participant. Participants received written instructions in L2 to perform a L2 lexical decision task. Care was taken to convince participants that the experiment was about L2 processing, to prevent awareness of the fact that L1 was crucial for the experiment. Instructions mentioned that ten practice trials and several experimental trials would follow. The participants were instructed to react to the target word and press one button if the presented letter string was an existing English (L2) word or another button if this was not the case. Half of the participants had to press the right button for word response, and the left button for a nonword. For the other half of the participants, this was reversed. All participants completed the 240 experimental trials in a random order. Each of the targets was presented only once.

Every trial started with the presentation of a centered fixation point ("+") for $800 \mathrm{~ms}$. Three hundred ms later, the word or nonword target was presented, centred on the screen. The target stayed on the screen until the participant responded, or until the maximum response time $(2500 \mathrm{~ms})$ was exceeded. The inter trial interval (ITI) was $700 \mathrm{~ms}$.

After the experiment, all participants completed a short questionnaire, assessing their self-reported L1 and L2 reading, speaking, writing and general proficiency level on a seven-point Likert scale. Also, the participants received a list with the cognate and control word targets to verify that they actually knew the L2 words.

\section{Results}

The proportion of incorrect responses to word targets was $4.56 \%$. These trials were excluded from all reaction time (RT) analyses. Also, RTs that were faster than $200 \mathrm{~ms}$ and RTs that were more than 2.5 standard deviations below or above the participant's mean RT for word targets were excluded from the analyses (2.36\% of the data). ANOVAs were performed across participants and across items with Target Type (cognate vs. control) and Overlap (identical vs. non-identical) as independent variables. The 
dependent variable was the mean RT across trials. For theoretically relevant cognate effects, effect sizes are indicated (Cohen's $d$ ). Additionally, because accuracy scores did not meet parametric testing criteria, we analyzed Target Type effects for identical and non-identical cognates using non-parametric sign-tests, which were also run across participants and across items. RTs for the non-identical cognate bread and its control horse were discarded from analyses because of an ungrammaticality in their sentence context for the following experiments (see further). Mean RTs and proportion of errors as a function of Target Type are presented in Table 3.

Insert Table 3 about here

Latencies. The effect of Target Type on RTs was significant: cognates $(M=555)$ were recognized more quickly than control words $(M=592 ; d=1.36), F_{l}(1,33)=30.35, p<.001, M S E=1499, F_{2}(1,27)=$ 15.27, $p<.001, M S E=1223$. Also, this cognate effect interacted with the degree of cross-lingual overlap: the facilitation effect was stronger for identical cognates than for non-identical cognates, $F_{I}(1,33)=4.31, p$ $=.045, M S E=1172$, an effect that was in the expected direction, but not significant, in the analysis by items, $F_{2}(1,27)=1,68, p=.205, M S E=1223$. Planned comparisons showed that the RT difference between identical cognates $(M=549)$ and their controls $(M=598)$ was significant $(d=1.18), F_{l}(1,33)=$ 23.11, $p<.001, M S E=1749, F_{2}(1,7)=11.32, p=.012, M S E=1010$. Similarly, non-identical cognates $(M$ $=567)$ were recognized faster than their controls $(M=591, d=0.82), F_{l}(1,33)=10.97, p=.002, M S E=$ $921, F_{2}(1,20)=5.82, p=.026, M S E=1297$.

The fact that the interaction effect between Target Type and Overlap did not reach significance in the analysis by items may be due to the small number of items in the identical cognate cognition. Also, there may be some variability in the size of the effect within the non-identical condition due to the variability in overlap of non-identical cognates with their translation equivalents. In order to assess this interaction in a more sensitive fashion using a continuous measure of cross-lingual similarity, we calculated the correlation between Van Orden's (1987) orthographic similarity of translation equivalents (described 
above) and the size of the cognate effect by items. As expected, this correlation was positive $(r=.21)$, suggesting larger cognate effects with increasing cross-lingual lexical similarity, but not significant $(p=$ $.27)$.

Accuracy. Participants made fewer errors on cognate trials $(M=3.7)$ than on control trials $(M=$ 5.5). Sign tests revealed that this difference was almost significant in the analysis by participants, $Z_{1}=1.70$, $p=.089, Z_{2}=0.00, p=.999$ Table 3 shows that this tendency was especially due to smaller error rates for identical cognates $(M=2.6)$, relative to their controls $(M=7.0)$, a difference which was significant in the analysis across participants, $Z_{1}=2.25, p=.024, Z_{2}=0.89, p=.371$. The small accuracy difference between non-identical cognates $(M=4.9)$ and their controls $(M=4.1)$ was not significant, $Z_{1}=0.40, p=.689, Z_{2}=$ $0.27, p=.789$.

\section{Discussion}

Experiment 1 was a replication of the L2 cognate facilitation effect (see earlier, e.g., Dijkstra et al., 1999; Van Hell \& Dijkstra, 2002). As expected, we obtained a cognate facilitation effect in a L2 lexical decision task: participants responded more quickly on cognate trials than on control trials. Moreover, the effect interacted with the degree of cross-linguistic overlap: the facilitation effect on the RTs was stronger for identical cognates (e.g., LIP) than for non-identical cognates (e.g., SHIP - SCHIP), which still yielded a significant facilitation effect. As for the accuracy data, participants also made fewer errors on cognate trials than on controls, but this cognate effect was only significant for the identical cognates in the analysis by participants.

First, these findings confirm earlier studies that also reported a L2 cognate facilitation effect (e.g., Dijkstra et al., 1999). This is an interesting finding because this is the first study after that of Van Hell and Dijkstra (2002) that obtained a cognate facilitation effect with stimuli that are mostly unambiguous with respect to the language to which they belong. Whereas other studies have often used a larger proportion of identical cognates and homographs, the present study used mostly near-cognates (only $6.67 \%$ of all word targets were identical cognates). This effect adds further strength to the growing body of evidence that 
lexical access in bilinguals is not language-specific. Second, at a methodological level, these findings show that the selected cognate/control word lists constitute an appropriate stimulus set to investigate lexical access by bilinguals in a sentence context.

\section{Experiment 2}

In Experiment 2, we investigated whether the strong unilingual context provided by a sentence affects lexical access of the same (near-)cognate and control words appearing at the end of that sentence. To be able to compare any cognate facilitation effect directly to the effect obtained in isolation, the present experiment also used a lexical decision task. Unlike previous studies of bilingual sentence reading however (e.g., Elston-Güttler et al., 2005; Van Hell \& Dijkstra, 2002), the target words in this experiment were actually a part of the preceding sentence. Similar to Schwartz and Kroll (2006), who studied word production, a SVP technique was used to implement serial word (sentence) reading.

\section{Method}

Participants. The participants were 33 additional Dutch-English bilingual volunteers. They were selected from the same population as the participants in Experiment 1, and had a similar L2 learning background. None of them participated in the first experiment. Of these 33 participants, 1 was excluded because of poor performance in the lexical decision task (his mean error rate was more than 2.5 standard deviations above the overall mean error rate). Mean self-assessed L1 $(M=5.9)$, L2 $(M=4.7)$ and L3 $(M=$ 4.1) general proficiency differed significantly (see also Table 1), $p$ s $<.001$.

Stimulus Materials. The critical target stimuli consisted of the 30 Dutch-English cognates (8 identical; 22 non-identical) and their 30 control words used in Experiment 1 (see Appendix A). For each of these pairs, a sentence was constructed that could contain both the cognate and its control as the final word (e.g., Lucia went to the market and returned with a beautiful CAT [cognate] / BAG [control]) (see Appendix B). Participants saw each sentence only once, with either the cognate or the control word as the target word. 
Therefore, two stimulus lists were used, counterbalanced over participants. Again, these lists were matched on word length, number of syllables, word frequency, and neighbourhood size ( $p$ s > .59).

Neither the cognates nor the control words were predictable from the sentence context. Similar to Schwartz and Kroll (2006) and Van Hell (1998; 2005), this was assessed in a sentence completion study, conducted with 23 participants from the same population who did not take part in any of the experiments. Participants were asked to complete the 30 sentences with an English target. As expected, mean production probabilities for identical cognates, non-identical cognates, and their control words were extremely low (identical: 0.005 , control: 0.005 ; non-identical: 0.047 , control: 0.043 ), similar to the production probabilities in the low-constraint conditions of Schwartz and Kroll (2006). Production probabilities for the two types of cognates and control words did not differ from each other (sign tests yielded $p s>.47$ ). In addition, we also conducted a rating study, in which 54 additional participants rated the predictability of the target words in the sentences on a six-point scale. Because the critical sentences were all low-constraint, we also included 30 filler sentences with a highly predictable final target word to make this rating task more natural. Sentences with identical and non-identical cognates as the final words were not rated as more predictable than sentences with the control words as the final words (identical: respectively $M=1.57$ and $M$ = 1.25; non-identical: $M=1.49$ and $M=1.24$, sign test $p \mathrm{~s}>.28$ ).

As non-critical stimuli, we also constructed 15 low-constraint filler sentences containing English filler target words and 45 filler sentences, which had nonword targets as the final words. These filler sentences were comparable to the sentences used for the cognates and control words, so that there were no linguistic cues that a nonword target would follow. The filler targets were taken from the filler targets of Experiment 1 and were matched with the critical (cognate/control) targets with respect to word length, number of syllables, word frequency and neighborhood size (see the Materials section of Experiment 1, ps $>$.10). As in Experiment 1, the nonword targets were all orthographically and phonologically legal English nonwords, constructed using the WordGen program (Duyck et al., 2004). As in Experiment 1, they were matched with the word targets with respect to word length (identical) neighborhood size, and summated 
bigram frequency ( $p$ s $>.45$ ), which may be considered a measure of a nonword's wordlikeness in a given language (Duyck et al., 2004).

Procedure. The procedure was identical to Experiment 1, except that participants were now instructed to perform a lexical decision task to word targets appearing as the final words of sentences, which were presented using SVP (see also Schwartz \& Kroll, 2006). Words were subsequently presented, centered on the screen during 700ms. This presentation rate is considerably slower than typical L1 RSVP experiments, because a pilot experiment indicated that this was the rate at which participants (of a similar L2 proficiency level) indicated that they could comfortably process the L2 sentences. Following earlier RSVP research (e.g. Wright \& Garrett, 1984), the appearance of the target word was indicated by a beep accompanying the preceding word, which also stayed somewhat longer on the screen (1200 ms). Target words were also presented in capital letters, as a cue to respond. The ITI was $1200 \mathrm{~ms}$. Each participant completed the 90 experimental trials (including fillers) in a random order. Each of the sentences was only presented once, either with the cognate or its control as the target word. To ensure that the participants actually read the sentences, we used the same recognition task as Elston-Güttler et al. (2005). After each block of ten sentences, four sentences were presented, two of which were shown in the preceding block. Participants had to indicate for each of these four sentences whether it appeared in the preceding block or not, pushing a button on a response box. Mean accuracy on this verification task was very high $(M=$ $90.9 \%, S D=5.6)$.

\section{Results}

The proportion of incorrect responses to word targets was $6.68 \%$. These trials were excluded from all RT analyses. The outlier criteria were the same as those described in Experiment 1 (2.74\% of data points were excluded). ANOVAs were performed across participants and across items with Target Type (cognate vs. control) and Overlap (identical vs. non-identical) as independent variables. The dependent variable was the mean RT across trials. For theoretically relevant cognate effects, effect sizes are indicated (Cohen's $d$ ). Again, accuracy scores were analyzed by means of non-parametric sign-tests, which were also run across 
participants and across items. Also, RTs for the non-identical cognate bread and its control horse were again discarded from all analyses because bread was preceded by an indefinite article $(a)$, which is grammatical is Dutch, but not in English (see Appendix B). Mean RTs and proportion of errors as a function of Target Type are presented in Table 4.

Insert Table 4 about here

Latencies. Similar to the isolation experiment (Experiment 1), The effect of Target Type on RTs was significant $(d=1.45), F_{I}(1,31)=32.40, p<.001, M S E=5506, F_{2}(1,27)=16.58, p<.001, M S E=$ 2881: cognates $(M=632)$ were recognized more quickly than control words $(M=706)$. Again, this cognate facilitation effect interacted with Overlap. The cognate effect was significantly stronger for identical than for non-identical cognates, $F_{l}(1,31)=7.88, p=.009, M S E=5451$, although this interaction did not reach significance in the analyses by items, $F_{2}(1,27)=2.45, p=.129, M S E=2881$. Planned comparisons showed that responses to identical cognates $(M=618)$ were significantly faster than responses to their control words $(M=729 ; d=1.21), F_{l}(1,31)=22.69, p<.001, M S E=8737, F_{2}(1,7)=9.34, p=.018, M S E$ $=3385$. Also, non-identical cognates $(M=646)$ were recognized faster than their control words $(M=684 ; d$ $=0.76), F_{l}(1,31)=10.42, p=.002, M S E=2220, F_{2}(1,20)=6.06, p=.023, M S E=2705$.

Finally, following the same logic as in Expeirment 1, we again calculated the correlation between Van Orden's (1987) orthographic similarity of translation equivalents, and the size of the cognate effect by items. This correlation was significant and positive, $r=.36, p=.05$. Hence, the size of the cognate effect increased as a function of lexical similarity between targets and their (near-) cognate translation equivalents.

Accuracy. Participants made fewer errors on cognate trials $(M=4.1)$ than on control trials $(M=$ 6.4). Sign tests revealed that this difference was not significant, $Z_{1}=1.49, p=.137, Z_{2}=0.75, p=.453$. Similarly, the large accuracy difference between identical cognates $(M=3.6)$ and their controls $(M=8.0)$ was not significant, $Z_{1}=1.12, p=.264, Z_{2}=0.50, p=.617$. The small accuracy difference between non- 
identical cognates $(M=4.6)$ and their controls $(M=4.8)$ was also not significant, $Z_{1}=0.21, p=.831, Z_{2}=$ $0.29, p=.773$

\section{Discussion}

The results were very similar to those of Experiment 1 . Again, we obtained a cognate facilitation effect. The two types of cognates (identical and non-identical) were recognized significantly faster than control words. Also, the cognate effect interacted with the degree of cross-lingual overlap. Facilitation was stronger for identical cognates than for non-identical cognates. Surprisingly, in absolute terms, the obtained cognate facilitation effects were larger in this experiment than in Experiment 1. However, mean RTs in this experiment were more than $100 \mathrm{~ms}$ slower, which makes it hard to compare these effects. Indeed, effect sizes for identical and non-identical cognate effects were similar in both experiments.

In conclusion, we replicated the cognate facilitation effect obtained earlier in isolated word recognition studies (Experiment 1; Dijkstra et al., 1999; Van Hell \& Dijkstra, 2002). These results offer strong evidence that lexical access in sentence reading by bilinguals is language-independent. Following earlier studies investigating word naming (Schwartz \& Kroll, 2006) and recognition of isolated target words outside the actual sentence (e.g., Elston-Güttler et al., 2005; Van Hell, 1998), this is the first study to demonstrate language-independent lexical access of words embedded in a sentence with a pure visual word recognition task.

\section{Experiment 3}

In this final experiment, we used the same set of cognates in an eyetracking paradigm. Because this technique does not require a response and allows participants to read normally, it excludes all factors inherent to experimental tasks, used in previous studies and in the previous experiments, as a source for cross-lingual lexical interactions. Also, its temporal resolution and sensitivity allow us to further investigate the timecourse of cross-lingual interactions. If these interactions occur during early stages of word recognition, as isolated visual word recognition studies suggest, cognate effects should be visible in early 
reading time measures. Given the fact that reasonably good correlations have been obtained between lexical decision and eye fixation times (Schilling, Rayner, \& Chumbley, 1998), it is therefore reasonable to assume that the cognate effects obtained in isolation (Experiment 1) should also show up in eyetracking results, if of course they are not nullified by sentence context.

\section{Method}

Participants. The participants were 34 additional Dutch-English bilingual psychology students from Ghent University, who received a small fee for participation. They were selected from the same population as the participants in the previous experiments, and had a similar L2 learning background. None of them participated in one of the previous experiments. They all had normal or corrected-to-normal vision. Mean self-assessed L1 $(M=5.9)$, L2 $(M=5.2)$ and L3 $(M=4.3)$ general proficiency differed significantly (see also Table 1), $p$ s $<.001$.

Stimulus Materials. The critical target stimuli consisted of the 30 Dutch-English cognates (8 identical; 22 non-identical) and their 30 control words used in Experiments 1 and 2 (see Appendix A). For each of these pairs, a sentence was constructed that could contain both the cognate and its control as one of the middle words. These sentences were based on the sentences from Experiment 2, but with a change in word order or with the addition of an extra phrase, so that the target word was no longer the final word of the sentence. (e.g., "Lucia went to the market and returned with a beautiful CAT [cognate] / BAG [control]" was changed to "Lucia returned with a beautiful CAT [cognate] / BAG [control] from the market") (see Appendix B). Participants saw each sentence only once, with either the cognate or the control word as the target word. Therefore, the same two stimulus lists were used as in Experiment 2, counterbalanced over subjects.

Both cognate and control words were not predictable from the sentence context. Similar to Experiment 2, this was assessed through a sentence completion study and plausibility ratings (see above). The completion study was conducted with 26 participants from the same population who did not take part in any of the experiments. Participants were asked to complete the 30 sentences expected to provide low- 
constraint contexts with an English target. As expected, mean production probabilities for identical cognates, non-identical cognates and their control words were again extremely low (identical: 0.005, control: 0.019; non-identical: 0.045, control: 0.058). As in Experiment 2, these production probabilities did not differ from each other (sign test $p s>.90$ ). For the rating study, 30 participants rated the predictability of the target words in the sentences using the same procedure as in Experiment 2. Identical and non-identical cognates did not yield higher predictability ratings than the control words (identical: respectively $M=1.08$ and $M=0.87$; non-identical: $M=1.14$ and $M=0.95$, sign test $p s>.28)$.

As non-critical stimuli, 30 filler sentences were constructed (mostly those from Experiment 2). Because the task was now reading instead of lexical decision, the nonword targets and their sentences were not longer needed.

Apparatus. Eye movements were recorded by a Senso-Motoric Instruments (SMI Eyelink) videobased pupil tracking system. Viewing was binocular but eye movements were recorded from the right eye only. A high speed video camera was used for recording. It was positioned underneath the monitored eye and held in place by head-mounted gear. The system has a spatial resolution of 20 seconds of arc. Fixation locations were sampled every $4 \mathrm{~ms}$ and these raw data were used to determine the different measures of oculomotor activity during reading. The display was $69 \mathrm{~cm}$ from the subject's eye and three characters equalled $1^{\circ}$ of visual angle. A chin rest was used to reduce head movements during the experiment.

Procedure. Before the experiment started, participants were informed that the study was about the comprehension of sentences that were displayed on a computer screen. Each sentence was presented as a whole on a single line of the screen in New Courier font. Participants were asked to read at their normal speed, and to answer any questions that would follow the sentence. These questions were simple comprehension questions following one fourth of the trials (only after filler trials). The participants had no difficulty answering these questions, with an overall accuracy rate of 97.6\%. Explaining the experiment to the participant combined with setting up the eye-cameras and calibrating the eye-tracking system took approximately 10 minutes. The calibration consisted of a standard nine-point grid. Following the initial calibration the participant was given 10 practice trials to become familiar with the procedure before reading 
the experimental sentences. The 30 experimental sentences were presented in a pseudo-random order, together with 30 filler sentences. Participants stopped a trial by pressing a button. The whole session lasted about half an hour.

\section{Results}

We examined the first fixation duration (FFD), the gaze duration (GD) and the cumulative region reading time (CRRT) on the target word ${ }^{3}$. We removed $6.7 \%$ of the data from the analyses because of track loss, because the fixation was shorter than $100 \mathrm{~ms}$ or because the reader did not start reading the sentence at the leftmost word (see Morrison, 1984; Rayner, Sereno, Morris, Schmauder, \& Clifton, 1989, for justification). For each measure, ANOVAs were again performed with Target Type (cognate vs. control) and Overlap (identical vs. non-identical) as independent variables, across participants and across items.

Mean fixation times across participants by Target Type and Overlap are shown in Table 5. The overall effect of Target Type was almost significant for the FFD on the target word, $F_{l}(1,33)=3.17, p=$ $.063, M S E=1539, F_{2}(1,27=4.24, p=.049, M S E=605$. This effect however, interacted significantly with the degree of cross-lingual overlap, $F_{l}(1,33)=4.21, p=.048, M S E=2010, F_{2}(1,27)=4.90, p=.036$, $M S E=605$. Planned comparisons showed that FFDs were significantly shorter $(M=249)$ for identical cognates than for their controls $(M=278 ; d=0.55), F_{l}(1,33)=4.97, p=.033, M S E=2823, F_{2}(1,7)=$ $6.77, p=.035, M S E=563$. Interestingly, this effect was not significant for non-identical cognates (both $F \mathrm{~s}$

$<1)$. For GDs, the effect of Target Type was also significant, $F_{l}(1,33)=7.71, p=.008, M S E=2393, F_{2}(1$, $27)=5.19, p=.031, M S E=1445$. Again, the effect of Target Type tended to interact with Overlap, $F_{l}(1$, $33)=3.73, p=.062, M S E=3473, F_{2}(1,27)=2.76, p=.108, M S E=1445$. Similar to the FFD analysis, planned comparisons showed that GDs were significantly shorter for identical cognates $(M=262)$ than for their controls $(M=305 ; d=0.65), F_{1}(1,33)=7.07, p=.012, M S E=4411, F_{2}(1,7)=8.67, p=.022, M S E$ = 893. Again, there was no cognate effect for non-identical cognates (both $F s<1$ ). A similar pattern of results emerged for CRRTs. The effect of Target Type was significant, $F_{I}(1,33)=4.32, p=.046, M S E=$ $7894, F_{2}(1,27)=4.30, p=.048, M S E=3780$, but its interaction with Overlap tended towards significance, 
$F_{I}(1,33)=2.54, p=.121, M S E=6489, F_{2}(1,27)=1.41, p=.246, M S E=3780$. Again, CRRTs were significantly shorter for identical cognates $(M=292)$ than for their controls $(M=346 ; d=0.61), F_{l}(1,33)=$ $6.09, p=.019, M S E=8042, F_{2}(1,7)=7.33, p=.030, M S E=1893$. There was no cognate effect on CRRTs for non-identical cognates (both $F \mathrm{~s}<1$ ).

Similar to Experiment 2, we also investigated whether the obtained cognate effects on FFDs correlated with Van Orden's (1987) orthographic similarity measure of targets and their (near-) cognate translation equivalents. Again, this correlation was significant and positive, $r=.37, p=.05$. Hence, the size of the cognate effect on FFDs increased as a function of lexical similarity between targets and their (near-) cognate translation equivalents.

Insert Table 5 about here.

\section{Discussion}

The analyses above showed clear cognate effects on the reading times of the target word for identical cognates, but not for non-identical cognates. Planned comparisons showed significantly faster FFDs, GDs and CRRTs for identical cognates than for their controls (effects of respectively 29, 43 and 54 $\mathrm{ms})$. There were no cognate effects at all for non-identical cognates (all $F \mathrm{~s}<1$ ).

In general, these results show that sentence context may nullify the L2 cognate effects obtained in isolation when cross-lingual activation spreading is weaker (non-identical cognates), but not when the lexical overlap between languages is at a maximum (identical cognates). Importantly, these strong effects for identical cognates already emerged during the first fixation of the targets. This is consistent with the notion in the literature that cross-lingual lexical interactions occur early during visual word recognition (e.g., Dijkstra et al., 1999). 


\section{General Discussion}

Earlier research has shown that lexical access in bilingual word recognition is not languagespecific, even when only one language needs to be activated to perform the experimental task (e.g., Brysbaert, Van Dyck, \& Van De Poel, 1999; De Groot et al., 1994; Dijkstra et al., 1999; Caramazza \& Brones, 1979; Dijkstra et al., 2000; Dijkstra et al., 1998; Duyck, 2005; Duyck, Diependaele, Drieghe, \& Brysbaert, 2004; Jared \& Kroll, 2001; Lemhöfer \& Dijkstra, 2004; Lemhöfer et al., 2004; Van Hell \& Dijkstra, 2002; Van Heuven et al., 1998; Van Wijnendaele \& Brysbaert, 2002). These findings, and therefore also the modeling of bilingual word recognition (the BIA+ model of Dijkstra and colleagues, e.g., Dijkstra, Grainger, \& Van Heuven, 1999; Dijkstra \& Van Heuven, 2002) are almost exclusively based on isolated word recognition studies. However, word recognition in both L1 and L2 (by bilinguals) rarely occurs out of context. Therefore, the goal of the present study was to investigate whether bilingual readers use the language of a sentence to guide lexical search/access towards lexical representations belonging to that specific language. More specifically, we tested whether the degree of cross-lingual interactions during word recognition is affected by the strong unilingual linguistic context that is provided by (sequences of) sentences. First, we will shortly summarize our main findings and relate them to earlier research on this issue. Second, we will discuss the theoretical implication of these findings.

In Experiment 1, we replicated the cognate facilitation effect, which several studies have obtained using various tasks, bilinguals, languages and stimuli (e.g., Costa et al., 2000; De Groot et al., 1994; Dijkstra et al., 1999; Lemhöfer et al., 2004; Van Hell \& Dijkstra, 2002). Using a L2 lexical decision task with word targets presented in isolation, we found that cognates are recognized faster (and more accurately) than control words. Also, this facilitation effect interacted with the degree of cross-lingual overlap: cognate facilitation was stronger for identical (e.g., LIP) than for non-identical cognates (e.g., SHIP). In Experiment 2, we replicated this effect with the same cognate and control targets as the final words of a low-constraint sentence, presented through SVP. Again, the effect interacted with the degree of cross-lingual overlap. Experiment 3 was set up to test whether the cognate facilitation effect could also be obtained with a more natural reading task. Eyetracking yielded shorter reading times for identical cognates, but not for non- 
identical cognates. These effects showed up in FFDs, GDs and CRRTs. This shows that the cross-lingual lexical interactions responsible for the cognate effect occur early in word recognition, which is consistent with the isolated word recognition literature (e.g., Dijkstra et al., 1999).

These findings have a number of theoretical implications. First, these findings add further strength to the growing body of evidence that lexical access in isolated word recognition by bilinguals is not language specific (Experiment 1). Additionally, the interactions of cognate status with the cross-lingual overlap also show that the amount of activation spreading from one language's lexical representation to another's, is a function of the similarity between the translation equivalents. Second, these findings show that the top-down linguistic context provided by sentences does not generate enough lexical restrictions to completely nullify the activation coming from the non-target language cognate representation (Experiments 2 and 3). Hence, bilingual readers do not use the language of a sentence as an early language selection cue to restrict lexical search to a particular language. Third, whereas sentence context does not render lexical access language-specific, it did interact with the degree of cross-lingual activation spreading. In Experiment 3 , eyetracking results showed that the low-constraint sentence contexts used in this study were strong enough to counteract the cognate facilitation effect in normal reading when cross-lingual activation transfer is weak (non-identical cognates), but not when it is at a maximum (identical cognates).

In general terms, our results are compatible with the few earlier studies on bilingual sentence reading discussed earlier. First, Van Hell $(1998 ; 2005)$ also obtained a cognate facilitation effect with targets that were primed by a sentence context. However, in her study, the targets were presented outside, and four seconds after the actual sentence (e.g., "a green --- and a yellow banana lay on the fruit dish"; target APPLE). This task is quite similar to a lexical decision task in isolation. The same applies to the study of Elston-Güttler et al. (2005). In her study, German-English homograph target words were also presented after a sentence (which had the target's prime as the final word, e.g. "the woman gave her friend an expensive gift", target POISON). Second, our results are very similar to those recently reported by Schwartz and Kroll (2006) for word production. They also reported a L2 cognate facilitation effect for cognate words appearing in a sentence context, using word naming, which also entails a production component. Because 
earlier production studies without a word recognition phase (e.g., picture naming, Costa et al., 2000) have also reported cognate effects, this production component may also have caused the cognate effect of Schwartz and Kroll. Therefore, the present study constitutes an important extension of their findings to pure word recognition (lexical decision, eyetracking). Also, the present study rules out a possible alternative explanation for Schwartz and Kroll's results. In their study, $84 \%$ of all word targets to be named (22 homographs +15 identical cognates, out of 22), were ambiguous with respect to the language to which they belong. This may have artificially increased the salience of the non-target language relative to more natural language contexts. Grosjean's language mode theory for example (1997; see also Soares \& Grosjean, 1984), suggests that the bilingual lexical system may function more or less language-independent, depending on the 'language mode' that a bilingual is in. Such a bilingual language mode may be activated for example by the presence of many language ambiguous words in the stimuli. Evidence that non-target language salience may influence the degree of cross-language interactions comes also from the study of Elston-Güttler et al. (2005). As indicated earlier, they found that interlingual homographs activated their non-target language's meaning, but only after participants had seen a non-target language movie prior to the experiment, increasing its salience. The $84 \%$ language ambiguous stimuli in the study of Schwartz and Kroll (2006) might have triggered a similar mechanism. This alternative explanation does not apply to the cross-lingual interactions found in the present study, because the proportion of language ambiguous stimuli was much lower and much more comparable to everyday language (e.g., Experiment 1: 6.67\%; Experiment 2: $17.8 \%)$

The effects observed for non-identical cognates also rules out an alternative explanation of the cognate effect, which does not necessarily imply language-independent lexical access. Gollan, Forster and Frost (1997) for example, have suggested that cognates may share the same lexical representation in the bilingual lexicon. Any cognate effect may then be a confound of a cumulative frequency effect, because cognates are encountered much more often (when reading both L1 and L2 texts). This account can not explain the current findings (and those obtained with non-identical cognates by Van Hell \& Dijkstra, 2002), because non-identical cognates cannot be represented through the same lexical representation (e.g. the 
orthographic representations of the near-cognates castle and kasteel are actually quite dissimilar). Note however that this does not rule out the possibility that identical cognate facilitation effects have a different origin than non-identical cognate facilitation, and are indeed due to the cumulative frequency hypothesis discussed above.

A second alternative explanation for the cognate effects obtained in this study concerns the fact that most (all but two) of our identical cognates were actually Dutch-English-French cognates ${ }^{4}$. Because our Dutch-English participants generally also had knowledge of French (mean self-reported general L3 proficiency ratings ranging from 3.6 to 4.3 ), it may be the case that the obtained identical cognate effects have arisen not only from activation spreading from L2, but also from L3. Indeed, Lemhöfer et al. (2004) reported faster responses to L3 words which are cognates with both L1 and L2 than for exclusive L3-L1 cognates. In our study, these L1-L2-L3 cognates yielded a mean facilitation effect of $62 \mathrm{~ms}$ in Experiment 1 for example, whereas L1-L2 cognates showed a $27 \mathrm{~ms}$ effect. However, this difference was not significant, $p>.37$, most likely because this test only contained two L1-L2 cognates. If the eight identical cognates were ranked according to the cognate effect that they elicited, exclusive L1-L2 cognates occupied ranks 3 and 8, which also suggests that the influence of this factor is rather limited. Additionally, reanalyzing our data with participants' L3 proficiency as a covariate in analyses by participants, and targets' lexical overlap with L3 translation equivalents (Van Orden's measure) as a covariate in analyses by participants, did not yield reliable L3 effects for any of the experiments. Finally, note that whereas this trilingual accumulative cognate hypothesis for identical cognate effects cannot be excluded with absolute certainty, we believe this would only add further strength to our claim of non-selective lexical access. Such a mechanism would imply that not only L1 influences L2 word recognition (which may be very plausible), but also that L3 lexical representations become activated during L2 processing in a sentence context, which is more surprising.

Finally, it is important to discuss the implications of the present study for the future development of models of bilingual language processing. At present, the most explicit model of visual word recognition in bilinguals is the BIA+ model of Dijkstra and Van Heuven (e.g., Dijkstra et al., 1999; Dijkstra \& Van 
Heuven, 2002). Following its predecessor (BIA), BIA+ is a bilingual extension of the well-known Interactive Activation (IA) model for monolingual word recognition (e.g., McClelland \& Rumelhart, 1981). In BIA+, language nodes have been added (supplementary to word, letter and feature nodes), and L2 words are represented in a unitary word-level lexicon. The model assumes that word recognition processes are initially non-selective, as word activation is affected by lexical representations from both languages. Therefore, the model can easily account for the cognate facilitation effects observed in Experiment 1. Also, by assuming that cross-lingual facilitatory activation spreading is a function of word similarity (much in the way intralexical activation is in the IA), the model may also explain our finding that cognate facilitation is stronger for identical cognates. Although the model was originally designed to explain empirical findings in out-of-context recognition tasks, its recent version may also still account for the sentence context effects obtained in this study. In BIA+ (unlike the previous BIA model), there are no top-down connections from language nodes; these nodes are just passive language tags (necessary for lexical decision). Influences of high-level factors are dealt with at a "task schema" level, which receives input from the non-selective word identification system. Both linguistic and non-linguistic factors may influence this task schema system, which in turn has a top-down influence on activation in the word identification system (the lexicon). Nonlinguistic factors may be instructions, task demands or task-related strategies. In this architecture, decision criteria, in a isolated lexical decision task for example, may change as a function of stimulus list composition (e.g., Dijkstra et al., 1998; Dijkstra et al., 2000; Dijkstra et al., 2000), without assuming that such top-down factors influence activation in the lexical representations itself. Linguistic factors may be of a lexical, syntactic or semantic origin, and may be provided by sentence context, like in the present study. Because we did not manipulate the semantic (or syntactic) context in which our target words appeared, the present study specifically investigated whether the linguistic context provided by a sentence is used by bilingual readers as an early language selection mechanism to guide lexical search of words appearing in that sentence, thereby influencing the functional selectivity of the fundamentally non-selective system.

The implications of our results with respect to this issue are twofold. First, the identical cognate effect obtained in Experiment 1 was still present in the sentence contexts of Experiments 2 and 3. This 
suggests that the influence of linguistic factors on cross-lingual interactions in the word identification system (lexicon) of the BIA+ model should be relatively small, and that lexical access during word recognition by bilinguals in sentence contexts is functionally not language-selective. Secondly, the eyetracking results from Experiment 3, suggest that unilingual linguistic sentence contexts may still interact with lexical variables such as cross-lingual overlap, thereby influencing the degree of cross-lingual activation transfer (the cognate effect). In normal reading, the sentence context effect was strong enough to counteract the cognate effect when the cross-lingual form overlap between translation equivalents was not complete (non-identical cognates), but not when it was at a maximum (identical cognates). In Experiment 2 however, which used a lexical decision task, the non-identical cognate effect, was still present despite the unilingual sentence context. This shows that the interactions in BIA+ between context and lexical variables may also interact with task-specific factors. It may be the case that lexical representations reach a stable state sooner in normal reading than in a lexical decision task, so that chances are smaller for weak crosslingual activation spreading (non-identical cognates) to influence word recognition. A similar mechanism might be responsible for the observations of Van Hell (1998) and Schwartz and Kroll (2006) that cognate facilitation disappeared in high-constraint sentences. In such sentences, lexical search and access may be speeded so much by the semantic feature restrictions imposed by the sentence, that non-target language representations have no chance to influence word recognition (even for identical cognates). Future modeling will have to show the plausibility of these speculative hypotheses.

To summarize, the cognate facilitation effects obtained in the present study offer strong evidence that lexical access in bilinguals may be language-independent both in isolated word recognition and in sentence embedded word recognition. The linguistic context provided by sentences may however interact with other lexical variables of words to be recognized, such as the degree of cross-lingual overlap of translation equivalents, and influence or even overcome the cross-lingual spreading of activation.

In conclusion, the interest for bilingual language processing has grown substantially during the last decade. However, the understanding of bilingual language processing is by far not at the level of the monolingual domain. We believe an important step to achieve this is to extend the present research in 
bilinguals to sentence processing. This may be one of the more important developments in bilingual research for the coming years. As one of the few studies on this issue, we hope that the present work may contribute to this. 


\section{References}

Altarriba, J., Kroll, J. F., Sholl, A., \& Rayner, K. (1996). The influence of lexical and conceptual constraints on reading mixed-language sentences: evidence from eye fixations and naming times. Memory \& Cognition, 24(4), 477-492.

Altenberg, E. P., \& Cairns, H. S. (1983). The effects of phonotactic constraints on lexical processing in bilingual and monolingual subjects. Journal of Verbal Learning and Verbal Behavior, 22(2), 174188.

Baayen, R., Piepenbrock, R., \& Van Rijn, H. (1993). The CELEX lexical database. [CD-ROM]. Philadelphia: University of Pennsylvania: Linguistic Data Consortium.

Balota, D. A., Pollatsek, A., \& Rayner, K. (1985). The interaction of contextual constraints and parafoveal visual information in reading. Cognitive Psychology, 17(3), 364-390.

Brysbaert, M., Van Dyck, G., \& Van De Poel, M. (1999). Visual word recognition in bilinguals: evidence from masked phonological priming. Journal of Experimental Psychology: Human Perception and Performance, 25(1), 137-148.

Caramazza, A., \& Brones, I. (1979). Lexical access in bilinguals. Bulletin of the Psychonomic Society, 13(4), 212-214.

Cole, R. A., \& Perfetti, C. A. (1980). Listening for mispronunciations in a childrens Story: the use of context by children and adults. Journal of Verbal Learning and Verbal Behavior, 19(3), 297-315.

Coltheart, M., Davelaar, E., Jonasson, J. T., \& Besner, D. (1977). Access to the internal lexicon. In Dornic, S. (Ed.), Attention and Performance VI. (pp. 535-555). New York: Academic Press.

Costa, A., Caramazza, A., \& Sebastian-Galles, N. (2000). The cognate facilitation effect: implications for models of lexical access. Journal of Experimental Psychology: Learning Memory and Cognition, 26(5), 1283-1296.

Cristoffanini, P., Kirsner, K., \& Milech, D. (1986). Bilingual lexical representation: the status of SpanishEnglish cognates. Quarterly Journal of Experimental Psychology Section a-Human Experimental Psychology, 38(3), 367-393. 
De Groot, A. M. B., Dannenburg, L., \& van Hell, J. G. (1994). Forward and backward word translation by bilinguals. Journal of Memory and Language, 33(5), 600-629.

Dijkstra, T., De Bruijn, E., Schriefers, H., \& Ten Brinke, S. (2000). More on interlingual homograph recognition: language intermixing versus explicitness of instruction. Bilingualism: Language and Cognition, 3(1), 69-78.

Dijkstra, T., Grainger, J., \& Van Heuven, W. J. B. (1999). Recognition of cognates and interlingual homographs: the neglected role of phonology. Journal of Memory and Language, 41(4), 496-518.

Dijkstra, T., Timmermans, M., \& Schriefers, H. (2000). On being blinded by your other language: effects of task demands on interlingual homograph recognition. Journal of Memory and Language, 42(4), 445-464.

Dijkstra, T., \& Van Heuven, W. (2002). The architecture of the bilingual word recognition system: from identification to decision. Bilingualism: Language and Cognition, 5(3), 175-197.

Dijkstra, T., Van Jaarsveld, H., \& Ten Brinke, S. (1998). Interlingual homograph eecognition: effects of task demands and language intermixing. Bilingualism: Language and Cognition, 1 (1), 51-66.

Duyck, W. (2005). Translation and associative priming with cross-lingual pseudohomophones: evidence for nonselective phonological activation in bilinguals. Journal of Experimental Psychology: Learning Memory and Cognition, 31(6), 1340-1359.

Duyck, W., Desmet, T., Verbeke, L. P. C., \& Brysbaert, M. (2004). Wordgen: a tool for word selection and nonword generation in Dutch, English, German, and French. Behavior Research Methods Instruments \& Computers, 36(3), 488-499.

Duyck, W., Diependaele, K., Drieghe, D., \& Brysbaert, M. (2004). The size of the cross-lingual masked phonological priming effect does not depend on second language proficiency. Experimental Psychology, 51(2), 1-9.

Ehrlich, S. F., \& Rayner, K. (1981). Contextual effects on word perception and eye-movements during reading. Journal of Verbal Learning and Verbal Behavior, 20(6), 641-655. 
Elston-Güttler, K. E., Gunter, T. C., \& Kotz, S. A. (2005). Zooming into L2: Global language context and adjustment affect processing of interlingual homographs in sentences. Cognitive Brain Research, 25(1), 57-70.

Elston-Güttler, K. E., Paulmann, S., \& Kotz, S. A. (2005). Who's in control? Proficiency and L1 influence on L2 processing. Journal of Cognitive Neuroscience, 17(10), 1593-1610.

Fischler, I., \& Bloom, P. A. (1979). automatic and attentional processes in the effects of sentence contexts on word recognition. Journal of Verbal Learning and Verbal Behavior, 18(1), 1-20.

Fischler, I., \& Bloom, P. A. (1980). Rapid processing of the meaning of sentences. Memory \& Cognition, $8(3), 216-225$.

Font, N. (2001). Rôle de la langue dans l'accès au lexique chez les bilingues: Influence de la proximité orthographique et sémantique interlangue sur la reconnaissance visuelle de mots [The role of language in lexical access in bilinguals: Influence of interlingual orthographic and semantic proximity on visual word recognition]. Unpublished Doctoral Dissertation, Université Paul Valery, Montpellier, France.

Gollan, T. H., Forster, K. I., \& Frost, R. (1997). Translation priming with different scripts: masked priming with cognates and noncognates in Hebrew-English bilinguals. Journal of Experimental Psychology: Learning Memory and Cognition, 23(5), 1122-1139.

Gollan, T. H., Montoya, R. I., Fennema-Notestine, C., \& Morris, S. K. (2005). Bilingualism affects picture naming but not picture classification. Memory \& Cognition, 33(7), 1220-1234.

Grainger, J. (1990). Word-frequency and neighborhood frequency-effects in lexical decision and naming. Journal of Memory and Language, 29(2), 228-244.

Grosjean, F. (1997). Processing mixed language: issues, findings, and models. In De Groot, A. M. B. and Kroll, J. F. (Eds.), Tutorials In Bilingualism: Psycholinguistic Perspectives. (pp. 225-254). Mahwah, NJ: Lawrence Erlbaum Publishers.

Jared, D., \& Kroll, J. F. (2001). Do bilinguals activate phonological representations in one or both of their languages when naming words? Journal of Memory and Language, 44(1), 2-31. 
Jared, D., \& Szucs, C. (2002 ). Phonological activation in bilinguals: evidence from interlingual homograph naming. Bilingualism: Language and Cognition, 5(3), 225-239.

Lemhöfer, K., \& Dijkstra, T. (2004). Recognizing cognates and interlingual homographs: effects of code similarity in language-specific and generalized lexical decision. Memory \& Cognition, 32(4), 533550.

Lemhöfer, K., Dijkstra, T., \& Michel, M. C. (2004). Three languages, one echo: cognate effects in trilingual word recognition. Language and Cognitive Processes, 19(5), 585-611.

Marian, V., \& Spivey, M. ( 2003). Bilingual and monolingual processing of competing lexical items. Applied Psycholinguistics, 24(2), 173-193.

Marian, V., Spivey, M., \& Hirsch, J. (2003). Shared and separate systems in bilingual language processing: converging evidence from eyetracking and brain imaging. Brain and Language, 86(1), 70-82.

McClelland, J. L., \& O'Regan, J. K. (1981). Expectations increase the benefit derived from parafoveal visual information in reading words aloud. Journal of Experimental Psychology: Human Perception and Performance, 7(3), 634-644.

McClelland, J. L., \& Rumelhart, D. E. (1981). An Interactive Activation Model of context effects in letter perception .1. An account of basic findings. Psychological Review, 88(5), 375-407.

Morrison, R. E. (1984). Manipulation of stimulus onset delay in reading: evidence for parallel programming of saccades. Journal of Experimental Psychology: Human Perception and Performance, 10(5), 667-682.

Rayner, K., Sereno S.C., Morris, R. K., Schmauder, A. R., \& Clifton, C. J. (1989). Eye movements and online language comprehension processes. Language and Cognitive Processes, 4, 1-50.

Rayner, K., \& Well, A. D. (1996). Effects of contextual constraint on eye movements in reading: a further examination. Psychonomic Bulletin \& Review, 3(4), 504-509.

Sánchez-Casas, R. M., Davis, C. W., \& Garcia-Albea, J. E. (1992). Bilingual lexical processing: exploring the cognate non-cognate dstinction. European Journal of Cognitive Psychology, 4(4), 293-310. 
Schilling, H. E. H., Rayner, K., \& Chumbley, J. I. (1998). Comparing naming, lexical decision, and eye fixation times: word frequency effects and individual differences. Memory \& Cognition, 26(6), $1270-1281$.

Schwanenflugel, P. J., \& Lacount, K. L. (1988). Semantic relatedness and the scope of facilitation for upcoming words in sentences. Journal of Experimental Psychology: Learning Memory and Cognition, 14(2), 344-354.

Schwanenflugel, P. J., \& Shoben, E. J. (1985). The influence of sentence constraint on the scope of facilitation for upcoming words. Journal of Memory and Language, 24(2), 232-252.

Schwartz, A. I., \& Kroll, J. F. (2006). Bilingual lexical activation in sentence context. Journal of Memory and Language, 55(2), 197-212.

Soares, C., \& Grosjean, F. (1984). Bilinguals in a monolingual and a bilingual speech mode: the effect on lexical access. Memory \& Cognition, 12(4), 380-386.

Spivey, M. J., \& Marian, V. (1999). Cross talk between native and second languages: partial activation of an irrelevant lexicon. Psychological Science, 10(3), 281-284.

Stanovich, K. E., \& West, R. F. (1981). The effect of sentence context on ongoing word recognition: tests of a 2-process theory. Journal of Experimental Psychology: Human Perception and Performance, $7(3), 658-672$.

Stanovich, K. E., \& West, R. F. (1983). On priming by a sentence context. Journal of Experimental Psychology: General, 112(1), 1-36.

Van Hell, J. (1998). Cross-language processing and bilingual memory organization. Unpublished Doctoral Dissertation, University of Amsterdam, Amsterdam, The Netherlands.

Van Hell, J. (2005). The influence of sentence context constraint on cognate effects in lexical decision and translation. In Cohen, J., McAlister, K. T., Rolstad, K., and MacSwan, J. (Eds.), Proceedings of the 4th International Symposium on Bilingualism. (pp. 2297-2309). Somerville, USA: Cascadilla Press.

Van Hell, J. G., \& Dijkstra, T. (2002). Foreign language knowledge can influence native language performance in exclusively native contexts. Psychonomic Bulletin \& Review, 9(4), 780-789. 
Van Heuven, W. J. B., Dijkstra, T., \& Grainger, J. (1998). Orthographic neighborhood effects in bilingual word recognition . Journal of Memory and Language, 39(3), 458-483.

Van Orden, G. C. (1987). A rows is a rose: spelling, sound, and reading. Memory \& Cognition, 15(3), 181198.

Van Wijnendaele, I., \& Brysbaert, M. (2002). Visual word recognition in bilinguals: phonological priming from the second to the first language. Journal of Experimental Psychology: Human Perception and Performance, 28(3), 616-627.

Weber, A., \& Cutler, A. (2004). Lexical competition in non-native spoken-word recognition. Journal of Memory and Language, 50 (1), 1-25.

Wright, B., \& Garrett, M. (1984). Lexical decision in sentences - effects of syntactic structure. Memory \& Cognition, 12(1), 31-45. 


\section{Appendix A}

Critical stimuli Experiments 1, 2, 3 and 4: Dutch-English cognates and their respective L2 control words. L1 (Dutch) translation equivalents of non-identical cognates are indicated between brackets.

\begin{tabular}{|c|c|c|}
\hline Cognate Type & L2 Cognate & L2 Control Word \\
\hline \multirow{8}{*}{ Identical } & bar & gun \\
\hline & chaos & abuse \\
\hline & fort & dive \\
\hline & $\operatorname{lip}$ & pig \\
\hline & plan & sign \\
\hline & ring & coat \\
\hline & sport & shark \\
\hline & test & sink \\
\hline \multirow{22}{*}{ Non-Identical } & apple [appel] & brush \\
\hline & author [auteur] & victim \\
\hline & bell [bel] & tail \\
\hline & book [boek] & head \\
\hline & bread [brood] & horse \\
\hline & castle [kasteel] & donkey \\
\hline & cat [kat] & bag \\
\hline & clock [klok] & witch \\
\hline & dance [dans] & smile \\
\hline & dream [droom] & smell \\
\hline & fist [vuist] & herb \\
\hline & flag [vlag] & jump \\
\hline & hammer [hamer] & pillow \\
\hline & hope [hoop] & fear \\
\hline & island [eiland] & forest \\
\hline & knee [knie] & bird \\
\hline & nation [natie] & border \\
\hline & nose [neus] & pool \\
\hline & paradise [paradijs] & boundary \\
\hline & pepper [peper] & cherry \\
\hline & rose [roos] & cave \\
\hline & ship [schip] & farm \\
\hline
\end{tabular}




\section{Appendix B}

\section{Sentence Contexts of Experiments 2, 3 and 4. Targets and control words are displayed in capital letters.}

Experiment 2 (final word targets)

1. Luke went to the supermarket and bought an APPLE / a BRUSH

2. The audience of the murderplay appreciated the great work by the AUTHOR / VICTIM

3. He waited impatiently to see the new $B A R / G U N$

4. The naughty boy pulled the cow's BELL / TAIL

5. Tim was baking pancakes when one of them fell on my воок / $H E A D$

6. The rich farmer gave the poor man a BREAD/ HORSE*

7. They were walking in the woods when they saw a grey CASTLE/ DONKEY

8. Lucia went to the market and returned with a beautiful CAT / $B A G$

9. In countries where a war is going on. there is a lot of CHAOS / ABUSE

10. It is a mistake to think that in the Middle Ages each village had his own $C L O C K$ / WITCH

11. I would like you to repeat that DANCE / SMILE

12. She became awake because of the weird DREAM / SMELL

13. The knight used his sword to cut off the FIST / HERB

14. The Olympic athlete was really proud of his FLAG / JUMP

15. The first price went to the child that made the most beautiful FORT / DIVE

16. They had a fight and she hurt him using a HAMMER / PILLOW

17. After the police paid him a visit, he had no more HOPE / FEAR

18. On our vacation to Madeira we saw a very beautiful ISLAND / FOREST

19. The shooter felt very guilty when he hit the child's KNEE / BIRD

20. The other children often laughed at Mike's fat LIP/PIG

21. The war moved up to the middle of the NATION / BORDER

22. Ten thousand euros is a lot of money for a new NOSE / POOL

23. The atmosphere changed so much we were sure we had reached the PARADISE / BOUNDARY

24. The awful dish tasted like PEPPER / CHERRY

25. He did not know what to do and waited desperately for the lord's $P L A N / S I G N$

26. Hilda was showing off her new RING / COAT

27. On their walk to the park. they saw a ROSE / CAVE

28. Uncle Mark sold his house and spent all the money on a SHIP / FARM

29. Mary wants to go see a very special type of SPORT / SHARK

30. Gary was working on the TEST/SINK

${ }^{a}$ This sentence was excluded from all analyses because the word bread may be preceded by an indefinite article in Dutch, but not in English. We thank an anonymous reviewer for this suggestion.

\section{Luke bought an APPLE / a BRUSH in the supermarket}

2. The work of the AUTHOR / VICTIM was appreciated by the audience of the murderplay

3. He wanted to see the new $B A R / G U N$ and waited impatiently

4. The naughty boy pulled the BELL / TAIL of the cow

5. One of the pancakes landed on my BOOK / HEAD because Tim was not careful baking them

6. The poor man got a BREAD / HORSE from the rich farmer*

7. They saw a grey CASTLE / DONKEY while they were walking in the woods

8. Lucia returned with a beautiful $C A T$ / $B A G$ from the market

9. There is a lot of CHAOS / ABUSE in countries where a war is going on

10. The idea that every village had its own CLOCK / WITCH in the Middle Ages is wrong

11. I would like you to repeat that DANCE / SMILE until it is perfect

12. The weird DREAM / SMELL woke her up

13. The knight cut off the FIST / HERB using his sword

14. His extraordinary FLAG / JUMP made the Olympic athlete really proud

15 The child that made the most beautiful FORT / DIVE received the first price

16. She hurt him using a HAMMER / PILLOW when they had a fight

17. He had no more HOPE / FEAR after the police paid him a visit

18. We saw a very beautiful ISLAND / FOREST on our vacation to Madeira

19. The shooter hit the child's KNEE / BIRD and felt very guilty

20. The other children often laughed at the fat LIP / PIG of Mike

21. The war moved up to the middle of the NATION / BORDER and became very violent

22. Ten thousand euros for a new NOSE / POOL is a lot of money

23. We were sure we had reached the PARADISE / BOUNDARY because the atmosphere changed so much

24. The dish tasted like PEPPER / CHERRY and was awful

25. He waited desperately for the lord's PLAN / SIGN because he did not know what to do

26. Hilda bought a new RING / COAT and showed it to everyone

27. They saw a ROSE / CAVE while they were walking in the park

28. Uncle Mark bought a SHIP / FARM with the money he had received after the sale of his old house

29. There is a very special type of SPORT / SHARK that Mary wants to go see

30. Gary was working on the TEST / SINK in the evening 


\section{Author Note}

Wouter Duyck, Department of Experimental Psychology, Ghent University, Ghent, Belgium.

This research was made possible by the Research Foundation-Flanders (FWO), of which the first and third author are postdoctoral research fellows, and of which the second author is a research fellow.

The authors are indebted to Janet Van Hell and Judy Kroll for earlier comments on these data.

Correspondence concerning this article should be addressed to Wouter Duyck, Department of Experimental Psychology, Ghent University, Henri Dunantlaan 2, 9000 B-Ghent, Belgium. E-mail should be sent to wouter.duyck@UGent.be. 


\section{Footnotes}

1. Interestingly, whereas this effect has become the textbook example for evidence against lexical autonomy, Caramazza and Brones (1979) did not interpret their cognate facilitation effect as such. Instead, the effect was used to distinguish between models of lexical access that required serial orthography to phonology coding, and parallel coding models.

2. Van Orden defines graphemic similarity (GS) between two letter strings as $O S=10([50 \mathrm{~F}+30 \mathrm{~V}$ $+10 C) / A]+5 T+27 B+18 E$ ) with $F=$ number of pairs of adjacent letters in the same order shared by word pairs, $V=$ number of pairs of adjacent letters in reverse order shared by word pairs, $C=$ number of single letters shared by word pairs, $A=$ average number of letters in the two words, $T=$ ration of number of letters in the shorter word to the number of letters in the longer, $B=1$ if the two words share the first letter, else $B=0$ and $E=1$ if the two words share the last letter, else $E=0$. Then 'standardized' orthographic similarity (OS) between word $\mathrm{X}$ and $\mathrm{Y}$ is $O S_{X Y}=G S_{X Y} / G S_{Y Y}$. For more details concerning this measure, we refer to Van Orden (1987).

3. The first fixation duration is the duration of the first fixation during the first passage through the respective region, independent of the number of fixations that were made on that word/region. The gaze duration (GD) is the sum of the fixations from the moment the eyes land on the word of interest (for the first time) until the moment they move off again. The Cumulative Region Reading Time (CRRT) can be defined as the time elapsing from encountering a given region for the first time until a region to the right of the interest-region is fixated. The difference between CRRT and GD is that regressions originating from a particular region are added to the CRRT of that region, but they are not added to the GD. In the literature, CRRTs are also often labelled regression path reading times. If the region of interest is skipped, this will be scored as a missing value for all these measures.

4. We would like to thank an anonymous reviewer for this suggestion. 
Table 1. Self-assessed ratings (7-point Likert scale) of L1 and L2 proficiency (Experiments 1, 2 and 3). Standard deviations are indicated between parentheses.

\begin{tabular}{ccccc} 
& Skill & Experiment 1 & Experiment 2 & Experiment 3 \\
\cline { 2 - 5 } & Writing & $5.8(1.0)$ & $5.8(0.8)$ & $5.9(1.0)$ \\
L1 (Dutch) & Speaking & $5.5(1.2)$ & $5.9(0.7)$ & $5.9(1.0)$ \\
& Reading & $6.1(0.9)$ & $6.2(0.8)$ & $6.1(1.0)$ \\
& General Proficiency & $5.7(0.9)$ & $5.9(0.6)$ & $5.9(0.8)$ \\
\hline \multirow{2}{*}{ L2 (English) } & Writing & $4.5(1.2)$ & $4.2(1.0)$ & $5.2(0.8)$ \\
& Speaking & $4.9(1.1)$ & $4.5(1.1)$ & $5.4(0.8)$ \\
& Reading & $5.3(1.0)$ & $5.2(0.9)$ & $5.7(0.8)$ \\
\hline L3 (French) & General Proficiency & $4.9(0.9)$ & $4.7(0.8)$ & $5.2(1.0)$ \\
\hline
\end{tabular}


Table 2. Stimulus examples and mean lexical characteristics (Experiments 1, 2 and 3) (standard deviations are displayed between parentheses). Reported $p$ values indicate significance levels of dependent samples comparisons between cognates and controls (matched item by item), and independent samples comparisons between identical and non-identical cognates. L1 translation equivalents are indicated between brackets.

\begin{tabular}{|c|c|c|c|c|c|}
\hline Condition & Example & $\begin{array}{c}\text { Number of } \\
\text { Letters }\end{array}$ & $\begin{array}{l}\text { Number of } \\
\text { Syllables }\end{array}$ & $\begin{array}{c}\text { Word } \\
\text { Frequency }^{\mathrm{a}}\end{array}$ & $\begin{array}{c}\text { Neighborhood } \\
\text { Size }^{\mathrm{b}}\end{array}$ \\
\hline L2 Cognates & $\begin{array}{c}\text { apple } \\
\text { [appel] }\end{array}$ & $4.67(1.1)$ & $1.30(0.5)$ & $1.79(0.4)$ & $7.27(6.1)$ \\
\hline L2 Control Words & $\begin{array}{c}\text { brush } \\
\text { [borstel] }\end{array}$ & $4.67(1.1)$ & $1.30(0.5)$ & $1.76(0.4)$ & $7.17(5.8)$ \\
\hline$p$ & & identical & identical & $>.99$ & $>.64$ \\
\hline L2 Identical Cognates & $\begin{array}{l}\text { ring } \\
\text { [ring] }\end{array}$ & $4.00(0.8)$ & $1.13(0.4)$ & $1.88(0.4)$ & $9.80(5.7)$ \\
\hline $\begin{array}{l}\text { L2 Non-Identical } \\
\text { Cognates }\end{array}$ & $\begin{array}{c}\text { cat } \\
{[\mathrm{kat}]}\end{array}$ & $4.90(1.2)$ & $1.36(0.6)$ & $1.76(0.4)$ & $6.40(6.1)$ \\
\hline$p$ & & $>.59$ & $>.98$ & $>.73$ & $>.46$ \\
\hline
\end{tabular}

${ }^{a}$ Logarithm of word frequency per million words according to the CELEX lexical database (word lemmata) (Baayen et al., 1993).

${ }^{\mathrm{b}}$ Neighborhood size (Coltheart et al., 1977) calculated using the WordGen program (Duyck et al., 2004) on the basis of the CELEX lemma database (Baayen et al., 1993). 
Table 3. Mean RTs (ms) and Accuracy (\% errors) across participants as a function of Target Type and Overlap (Experiment 1: isolation). Standard errors are indicated between brackets. Asteriks (*) indicate significance levels of planned comparisons between cognates and their controls, respectively across participants (before the comma) and items (after the comma). L1 translation equivalents are indicated between brackets.

\begin{tabular}{cccc} 
& Example & RT & Accuracy \\
\hline Identical Cognates & LIP [lip] & $549(11.3)$ & $2.6(0.9)$ \\
Controls & PIG [varken] & $598(14.4)$ & $7.0(1.6)$ \\
Effect & & $49^{* * * * *}$ & $4.4^{*, n s}$ \\
\hline Non-Identical Cognates & SHIP [schip] & $567(10.4)$ & $4.9(1.1)$ \\
Controls & FARM [boerderij] & $591(15.1)$ & $4.1(1,0)$ \\
Effect & & $24^{* * * *}$ & $-0.8^{n s, n s}$ \\
\hline$p<.05,{ }^{* * *} p<.01,{ }^{* * * *} p<.001,{ }^{n s}$ not significant &
\end{tabular}


Table 4. Mean RTs (ms) and Accuracy (\% errors) across participants as a function of Target Type and Overlap (Experiment 2: SVP). Standard errors are indicated between brackets. Asteriks (*) and plussigns (+) indicate significance levels of planned comparisons between cognates and their controls, respectively across participants and items.

\begin{tabular}{ccc} 
& $\mathrm{RT}$ & Accuracy \\
\hline Identical Cognates & $618(17.5)$ & $3.6(1.3)$ \\
Controls & $729(25.9)$ & $8.0(1.9)$ \\
Effect & $111^{* * *, *}$ & $4.4^{n s, n s}$ \\
\hline Non-Identical Cognates & $646(17.5)$ & $4.6(1.4)$ \\
Controls & $684(24.1)$ & $4.8(1.2)$ \\
Effect & $38^{* * * * *}$ & $0.2^{n s, n s}$ \\
\hline$p<.05,{ }^{* *} p<.01,{ }^{* * * *} p<.001,{ }^{n s}$ not significant &
\end{tabular}


Table 5. First fixation duration (FFD), gaze duration (GD) and cumulative region reading time (CRRT) on the target word. FFD, Reported means are presented (in ms) as a function of Target Type and Overlap. Standard errors are indicated between brackets. Asteriks $\left(^{*}\right)$ and plus-signs $(+)$ indicate significance levels of planned comparisons between cognates and their controls, respectively across participants and items.

\begin{tabular}{|c|c|c|c|}
\hline & \multicolumn{3}{|c|}{ target word $_{n}$} \\
\hline & FFD & GD & CRRT \\
\hline Identical Cognates & $249(8.2)$ & $262(9.8)$ & $292(12.5)$ \\
\hline Controls & $278(9.5)$ & 305 (12.0) & $346(15.9)$ \\
\hline Effect & $29^{*}, *$ & $43^{*, *}$ & $54^{*, *}$ \\
\hline Non-Identical Cognates & $252(7.5)$ & $283(10.1)$ & $345(15.1)$ \\
\hline Controls & $249(7.2)$ & $287(10.0)$ & $355(16.0)$ \\
\hline Effect & $-3^{n s, n s}$ & $4^{n s, n s}$ & $10^{n s, n s}$ \\
\hline
\end{tabular}

